CASE STUDY

\title{
Duke Kunshan University A Case Study of Implementing Online Learning in Two Weeks
}

March 13, 2020

Kevin Guthrie

Catharine Bond Hill

Martin Kurzweil

Cindy Le

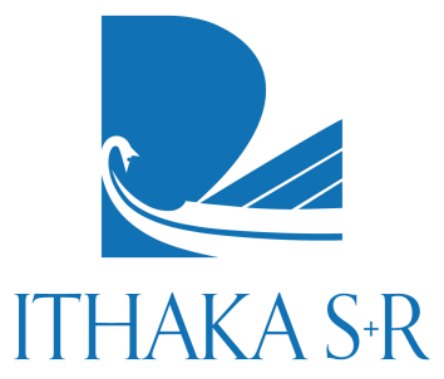




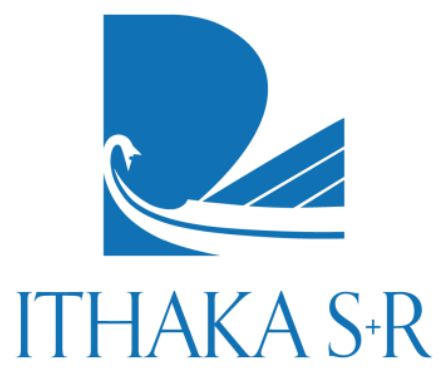

Ithaka $\mathrm{S}+\mathrm{R}$ provides research and strategic guidance to help the academic and cultural communities serve the public good and navigate economic, demographic, and technological change. Ithaka $S+R$ is part of ITHAKA, a not-for-profit organization that works to advance and preserve knowledge and to improve teaching and learning through the use of digital technologies. Artstor, JSTOR, and Portico are also part of ITHAKA.
Copyright 2020 ITHAKA. This work is licensed under a Creative Commons Attribution-NonCommercial 4.0 International License. To view a copy of the license, please see http://creativecommons.org/licenses/by-nc/4.0/.

ITHAKA is interested in disseminating this brief as widely as possible. Please contact us with any questions about using the report: research@ithaka.org. 


\section{Acknowledgements}

We would like to thank the entire Duke Kunshan and Duke teams who generously shared their experiences with us. Special thanks to Matthew Rascoff (Learning Innovation), Amy Kenyon (Learning Innovation) and Shawn Miller (Learning Innovation) of Duke University, Noah Pickus (Curricula Affairs and Faculty Development) and Haiyan Zhou (Center for Teaching and Learning) of Duke Kunshan and Duke, and Marcia France (Undergraduate Studies) of Duke Kunshan.

\section{Introduction}

The rapid spread of COVID-19 has led a large number of residential, primarily face-toface American colleges and universities to shift to remote courses for indefinite periods of time. This is a major disruption to normal activities, with pedagogical, social, and economic consequences. It is also a significant organizational and change-management challenge, with a short timeline and no safety net. Duke Kunshan University in Kunshan, China was one of the first US-affiliated institutions that had to deal with this, given the origin of the COVID-19 outbreak. Learning from its experience may be helpful to others in this instance or in the future.

In February 2020, Duke Kunshan University (DKU) made the decision to finish the third semester of its relatively new bachelor's degree program online, in response to the COVID-19 outbreak. In this case study, we document the decision-making and implementation of this move to online in a rapidly evolving situation in an effort to assist other colleges and universities as they decide how to proceed.

We believe there are lessons to be learned both about the response to this specific crisis and the role that technology can play in risk management and business continuity, but also the potential benefits of technology in the longer run in addressing the challenges that higher education is facing in terms of cost and access. We focus on the former in this brief, but will start to document some of the longer-term issues and lessons.

\section{Duke Kunshan University}

Duke Kunshan University (DKU) was co-founded by Duke University and Wuhan University to offer a liberal arts and sciences education in Kunshan, China. Duke has offered graduate level degrees at DKU since 2014, but the liberal arts bachelors is new; DKU matriculated its first class of BA students in 2018. As it ramps up to being fully enrolled, DKU currently has two classes of students. The university's 587 students and approximately 100 faculty members have been recruited from around the world, and 
these numbers will continue to grow until all four classes are matriculated. Students have the option to study abroad during their junior year at Duke or other institutions, so, even when it is operating at planned capacity, there will be fewer than four full classes on campus at any one time. ${ }^{1}$

\section{The crisis}

While students and faculty were on holiday for the Chinese New Year in January 2020, the COVID-19 outbreak in China occurred. Many students and faculty were off campus, distributed around China and the world. Just over half of DKU's undergraduate students are from China. With travel restrictions, it was clear that classes as normal were not going to be able to resume. Many airlines canceled return flights to China until later in the spring and travel restrictions within China also meant that many students, faculty and staff were not going to be able to return to campus. ${ }^{2}$

The academic year at DKU consists of four seven-week terms. Session three had started before the holiday, with three weeks remaining in the term. Rather than cancel the remainder of the session, the decision was made by the administration of Duke Kunshan, with input from faculty and staff, as well as the Duke administration, to complete session three online. 3

\section{The decision to move online}

There was significant faculty buy-in and support for this decision. Being a new institution, the faculty are innovative and willing to try new things, perhaps more so than at many other institutions. There was a sense of how important continuing to operate was going to potentially be to the future of the institution. There was also a real desire to be responsive to students, who were clearly unsettled by the crisis. Continuing the session and their education was considered an obligation, if feasible.

\footnotetext{
${ }^{1}$ See Duke Kunshan's website, dukekunshan.edu.cn/en.

2 See "China Travel Advisory," US Department of State-Bureau of Consular Affairs, February 2, 2020, https://travel.state.gov/content/travel/en/traveladvisories/traveladvisories/china-travel-advisory.html.

${ }^{3}$ See Zach Fredman, "Teaching Remotely While Quarantined in China," The Chronicle of Higher Education, March 11, 2020, https://www.chronicle.com/article/Teaching-Remotely-While/248226.
} 


\section{Planning for resuming classes online}

Since the only option was going online and this decision was made quickly, faculty and staff worked to get their courses organized to do so as quickly as possible. Once the decision was made, the university had to make some key decisions to support the effort.

\section{Technology decisions}

With the need for a speedy implementation, DKU decided to rely mostly on technologies that were already in place, with one exception. One benefit of this decision is that faculty and staff were already familiar with the technology.

The learning management system at DKU is Sakai, and all faculty were already using it. Some additional Sakai functionality was implemented, along with training, to meet particular needs. This included faculty using forums to communicate with each other and share best practices. Sakai also served as a repository for updates, FAQs, announcements, important resources on online pedagogy, and how-to guides.

For video conferencing, DKU quickly implemented Zoom. This required a new license in China, which had previously been unavailable, as well as training and support for faculty and staff.

Students, staff, and faculty use WeChat for informally communicating with each other, but the decision was made not to use it as the main form of communication or for classes. This decision was made in part for security reasons. Because it is fairly universally used by students and faculty, it has been an effective way of communicating briefly with individuals when needed, particularly for checking in with individual students who faculty notice are not engaging or responding to other means of communication. It is being used, therefore, just in special circumstances for getting in touch when other methods have failed.

\section{Pedagogy decisions}

Being a liberal arts college with an emphasis on small classes and active learning created challenges for moving online. While it was not going to be possible to completely

replicate this experience, it was understood that technology could be used so that students and faculty could continue teaching and learning.

While Zoom allows for synchronous video conferencing, there were concerns about relying excessively or exclusively on synchronous meetings, particularly because of the 
various time zones where faculty and students were located. Coordinating synchronous meetings was going to be extremely difficult and make everyone's participation more challenging. There were also concerns that some students might not have access to the required internet services. (More on this below.)

As a result, asynchronous aspects to each course were given particular attention.

The DKU team members were very concerned about treating students equitably, but every student was facing a different situation. This requires trade-offs. The DKU team decided that equity would be a guiding principle. This led to some decisions, for example, the extent to which to rely on synchronous versus asynchronous teaching and learning, with concerns that equitable access would be harder with synchronous classes. But, faculty are worried that asynchronous work might be more isolating in many circumstances and believed that more synchronous interactions would improve the student experience. But not all students would be able to fully participate. This is a tradeoff, and other institutions might have made a different decision, for instance if their students are less geographically dispersed and had more consistent access to the internet.

One of the lessons from session three was that students and faculty wanted more ways to engage and connect with each other. It was also found that improvements in technologies, including the VPN, enabled more students to have access to the tools needed for synchronous instruction. Students are therefore encouraged during session four to participate in live sessions, but if they cannot make it live and need to watch later, they will still be held harmless with respect to grading and participation.

As a small liberal arts college with mostly small classes, seminars are more common than lectures, although some faculty, especially those in STEM fields, still relied on lectures for many of their classes. With the move to online, the limitations of lectures are becoming even more obvious to faculty, as online lectures allow for no engagement with students in the moment. As students comment about challenges with motivation, faculty are examining their pedagogy and realizing the limitations of some of their practices.

\section{Helping the faculty get ready}

To help faculty get started, the support team started with their learning objectives for their courses. As a new institution, DKU has an advantage-all syllabi are standardized and the courses were developed with an emphasis on course design to accomplish specific learning objectives. Moving online didn't mean designing an entirely new course, but finding a different way to meet these learning objectives. 
Faculty were already trained and comfortable with backwards course design, working from learning objectives to course structure. All faculty had received training when initially joining DKU through a learning innovation fellowship program. DKU, being a new institution, implemented a syllabus approval process that would be difficult to put in place at more traditional institutions. Embedding learning objectives and active learning in courses was a focus of the onboarding training and are important to the syllabus approval process.

The support team also worked with faculty to think about the first few weeks as a way of getting started, so that the task would not seem insurmountable.

Sakai was used as the place to share information and keep everyone informed. This way, faculty had one place to go for information. This was easier and more efficient than email. Faculty members and key academic support staff were enrolled in a site that is used for updates and FAQs, announcements, important resources on online pedagogy, and how-to-guides. A discussion forum was set up to encourage faculty to post questions to get help and for sharing anything they wanted to share with their colleagues. In addition, in using Sakai to communicate early on, faculty who were less familiar with the LMS were using it for their own needs, which then prepared them to use it for their classes.

The Center for Teaching and Learning at DKU ran a number of webinars on a variety of topics to help faculty prepare. These included such topics as "Best Practices for Communication, Interaction and Building Community Online," "Effective Online Class Sessions with Zoom," "Building Online Community: Student engagement with content, instructors and peers," as well as others. While faculty in the normal course of faculty development have in the past had access to this type of training, the need to move online quickly created an incentive to invest the time in these webinars. Faculty participation was higher than normal.

Faculty assistance for specific needs became an issue as well. A system was set up for submitting a request for help, and the tech team triaged the responses, as well as sharing the information more broadly.

Given the time zone challenges, it was important to have help available 24/7. Because staff at Duke and DKU are located on opposite sides of the world, this proved to be easier than it might have been otherwise. This could be more challenging for some institutions moving online. Figuring out 24/7 assistance will be important, because small problems for individual faculty or students can keep them from being able to participate. 


\section{Helping the students and their families get ready}

DKU held webinars for students and their families so that they could understand how the university was moving forward. This was in addition to many other communications, but allowed for students and families to ask questions and hear from other students and families about their concerns. This was an efficient way of communicating and reassuring students and families about the options going forward.

As with the faculty, the Sakai site is the repository for all information and announcements. It includes detailed how-to guides on using various tools, links to IT support, tips for taking online courses, and a forum for students to ask questions and troubleshoot.

\section{Other services of DKU in addition to coursework}

Like any residential college or university, the academic courses are just one part of the educational experience. DKU worked to make other services available online as well.

- Counseling. Many institutions contribute to student well-being through a variety of services, from mental health services to physical education programs. DKU worked to make these services available to their students away from campus. For mental health services, the counseling team has offered online individual sessions as well as group Zoom sessions. Physical education classes have also continued. These courses included synchronous yoga, Pilates, tai chi, boxing and various workouts.

- Faculty office hours were moved online. Student access to faculty is an important part of the learning experience. In many ways, moving office hours online was one of the simpler adjustments. Each faculty member holds two hours of office hours online each week.

- Zoom rooms were created for peer support. The rooms are open 24/7 where students can drop in and help each other. There are also set times when the rooms are staffed. The writing center also has individual appointments for students.

- Academic accommodations. Given the unique circumstances, the administration decided to be as accommodating as possible around individual requests. Students have been given more flexibility to drop courses or to take course overloads. Some students are finding themselves in situations where there 
is little else going on, so that a course overload is not just manageable but helps stave off boredom. Other students are being granted leaves of absence, with little financial or academic penalty, when the change in pedagogy from in-person to online is not working for them for whatever reason.

- Student and faculty surveys. While careful not to add additional work for faculty and students, DKU has surveyed both to evaluate how the transition to online has worked and to identify areas for attention going forward.

\section{Challenges and lessons learned}

\section{Communications}

During any crisis, communication is always key and a challenge. There are many channels, and not everyone needs to know everything. The most important thing is to coordinate the communications that are taking place and make it extremely easy for all constituencies to find the information that they need.

Creating a high level emergency task force, as with any crisis, is helpful. Putting someone in charge of coordinating communications is also key. They can't be a bottleneck. Instead, their job is to make sure someone is paying attention to the overall coordination of communications.

\section{Getting students the resources they needed}

Because students and faculty left campus for holiday, many did not have either their computers or their course materials with them. Everyone, however, could communicate given the proliferation of smart phones, and DKU worked to make sure everyone had access to computers. This involved actually mailing laptops to some students.

Some students also did not have access at home to adequate internet services. DKU made financial arrangements to supplement services for students who needed this. More than half of students are in China. Access to the online program requires a VPN, which slows down internet access. This has made the use of some resources, such as multimedia, more difficult.

\section{Course materials}

There have been some challenges for instructors who assigned printed course materials and books since some students didn't take them with them on holiday. Also, some 
electronic content could not be accessed due to licensing limitations, although the publishers have tended to be liberal about allowing access. Faculty have therefore sought materials that could be accessed online, if not already available through the LMS.

Coursera stepped up and made all of its 4,000 courses available to all DKU students and faculty. Faculty could use modules, videos, or any other materials for their online courses. Students who wanted to could also take Coursera courses, as a way of continuing to learn while isolated at home. While these are not credit bearing at DKU, they give students the opportunity to continue learning on their own.

\section{Grading}

For some courses, evaluation online created evaluation challenges. Closed book exams create some academic integrity issues not faced with in-class exams. Faculty have responded in a variety of ways, from writing closed book exams that are timed and designed such that using course materials wouldn't help much, to offering open book exams, to using evaluation methods that involve more writing and submitting materials. Class participation is also difficult to weight in important ways, when access to video is differentially available.

Going forward, and with more time to prepare, DKU is investigating proctoring options for high stakes exams.

\section{Student isolation and motivation}

Students are reporting that it can be difficult to concentrate on the course materials. It is not unexpected that this situation is causing stress for the students. They had hoped to be on campus with faculty and peers, and instead are at home and isolated. DKU faculty are not just dealing with moving to an online format, but they are dealing with their students finding themselves in a stressful-and in some cases a crisis-situation.

Otherwise strong and motivated students are finding engagement difficult. Faculty and their support teams are working to help students engage, by increasing their responsibilities for the classes and also increasing peer-to-peer interaction.

\section{Lab classes}

Faculty teaching some subjects that rely on labs are finding it more difficult to accomplish the learning objectives online, particularly in an emergency situation. With time, there will be investment in online versions of labs that accomplish similar objectives to in-person labs. 
One solution involves doing the course work now and doing the labs later when back on campus. This may not be ideal in all situations, but some science courses are already taught this way, and it can allow students to continue their learning and not just postpone these courses.

\section{Experiential education}

DKU has a weekly schedule that includes Fridays without classes to allow for more experiential learning. The faculty are considering how to continue these experiences with students and faculty distributed around the world. 4

\section{Financial issues}

Facing this crisis will have important financial implications for all institutions affected. In the case of DKU, the decision was made to offer students and families a variety of options in terms of tuition payments and enrolment. This will of course mean that tuition revenue will likely be reduced, perhaps significantly. In addition, there are added costs of moving to online.

For each institution, the costs of addressing this crisis situation will differ but potentially could be significant. This is not different than other crises, such as hurricanes or other weather related disasters, and the response has been similar, in that institutions have to respond as best as possible, balancing protecting their missions with available resources.

DKU had the advantage of the ongoing relationship with Duke University, which meant that it could call on support in a variety of ways, from financial to people, as well as a location for many of the faculty outside of China to come together to work.

\section{Longer Run Issues}

Session four is scheduled to start on March 23, just three days after session three finishes. As of mid-March, it is unclear when the campus will be allowed to open. In the meantime, DKU is planning on continuing session four online if needed. There is very little time between the end of session three and the start of session four, so that there will not be time for significant course redesign for the final session of the year. The assumption is that by the next academic year, classes will resume on campus.

\footnotetext{
${ }^{4}$ See Zach Fredman, "Teaching Remotely While Quarantined in China," The Chronicle of Higher Education, March 11, 2020, https://www.chronicle.com/article/Teaching-Remotely-While/248226.
} 


\section{ITHAKA S+R}

Will courses be designed going forward with the possibility of moving to online in an emergency? Having lived through this experience, faculty may be encouraged to think about this possibility while designing their courses. We may be living in a world where this possibility arises more often.

Will institutions move to make sure that this option is available to them if needed as part of their risk management strategies? This might mean making sure faculty have some basic knowledge of the needed technologies, perhaps using them for part of their oncampus courses so that they are prepared to shift to online when needed. One could think of this as a fire drill of sorts.

Will this experience increase the use of OERs for courses? This would generate some cost savings and also guarantee continuity if forced to move online.

\section{Additional resources}

DKU has created a website with links to communications and a variety of resources made available to the DKY community: https://dukekunshan.edu.cn/en/news/specialmessage-novel-coronavirus 